challenge. Given the fact that cases of fraud demonstrably make it through refereeing processes, and given the importance of public trust in science, it proposes that journals apply additional scrutiny and risk assessment to papers that are likely to have a significant public impact, such as those with direct implications for policy, public health or climate change. The additional scrutiny recommended by the panel includes greater attention to raw data and a clarification of the contributions of each co-author.

We at Nature, like the editors at Science, accept that this challenge has to be addressed, and we have accepted their invitation to deal with such matters collaboratively. The key is to raise editors' and referees' practical awareness of the risk of deception. A conscious risk assessment, in which the likelihood of deception is explicitly analysed, is much easier said than done. An elementary checklist of risk factors can readily be introduced. But it would, for example, be quite inappropriate to single out papers from Seoul National University, or on human embryonic stem cells, and apply higher thresholds of proof to them.

On the other hand, we do already seek to ensure that major claims are backed by rigorous data and argument. Nevertheless, the sad fact is that high-profile and problematic papers have occasionally slipped through the net, and we accept that this underlines the need for enhanced attention by editors.

Nature and the Nature research journals already encourage the specification of authors' contributions to papers, and the uptake of this by authors has increased greatly in the past year - a fact that is welcomed by some funding agencies. We now intend to conduct a survey to help us decide whether to make this practice compulsory, and we would welcome readers' feedback.

It is an interesting question whether a more open peer-review process might have led to the detection of Hwang's fraud. At present, however, the level of interest in open peer review is too small to hope for such an outcome. That, at least, is the implication of Nature's trial of open peer review, the results of which can be found in an online debate on the subject (www.nature.com/nature/peerreview/debate/ nature05535.html).

In the trial, the papers selected for traditional peer review were, in a parallel option offered to authors, hosted for public comment. In the event, $5 \%$ of authors took up this option. Although most authors found at least some value in the comments they received, they were small in number, and editors did not think they contributed significantly to their decisions.

This was not a controlled experiment, so in no sense does it disprove the hypothesis that open peer review could one day become accepted practice. But this experience, along with informal discussions with researchers, suggests that most of them are too busy, and lack sufficient career incentive, to venture onto a venue such as Nature's website and post public, critical assessments of their peers' work.

Another form of peer review emerges after publication, when work is replicated - or not. If this kind of discussion is to make it into the open, rather than be confined to gossip at conferences, it requires a forum where peers are able to comment on individual papers, with minimal editorial intervention. Would commenting on Nature papers be more widely adopted by researchers after they have been formally published than before? We intend to introduce this function next year, and find out.

\section{Days of Futures past}

\section{It's a time of change for Nature's venture into speculative fiction.}

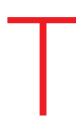
his week features the last in the series of 'Futures', Nature's occasional excursion into speculative fiction (as science fiction, or SF, is sometimes known). Since 1999, Nature has published no fewer than 156 such journeys into things to come, ranging from the serious to the whimsical, all of which (hopefully) provided some entertainment.

And that's the key - SF is meant to amuse in the present. The most memorable SF works do this by projecting our present concerns onto the greater canvas of uncertainty that is the preserve of that part of history that hasn't happened yet. Or, to put it more succinctly, "it is difficult to make predictions, especially about the future", a sentiment usually attributed to baseball star Yogi Berra. That it might sometimes be found attached to Sam Goldwyn, Woody Allen or even Niels Bohr demonstrates its fundamental soundness - and also, perhaps, that the past is as unreliable as the future.

Addressing this very issue, one visionary bucked the trend in the grandest fashion, writing in 1902 that "the time is drawing near when it will be possible to suggest a systematic exploration of the future". This is a bold statement indeed, but one that makes more sense if it is recognized that science is a necessarily predictive endeavour. As if to prove his point, the writer went on to outline a startling version of statistical mechanics in which the behaviour of large numbers of humans could be predicted, presaging Isaac Asimov's future science of psychohistory (in his 'Foundation' novels) by half a century.

Later still, the writer notes that "the question what is to come after man is the most persistently fascinating and the most insoluble question in the whole world", touching, even if coincidentally, on the theme of post-humanity that animates much current SF, itself a reaction to cloning and genetic manipulation.

Who was this visionary? It was none other than H. G. Wells, writing in these very pages (Nature 65, 326-331; 1902). From this we can derive some comfort that 'Futures' in Nature has indeed a venerable past.

And even now, we haven't quite come to the end of eternity. An anthology of the best of Futures is planned, and the column itself will continue, for a while,

\section{"An anthology of the best of Futures is planned, and the column itself will continue, for a while, in Nature Physics."} in our sister publication Nature Physics. So for a little longer, at least, we can share the emotions of Wells' Time Traveller (in his 1895 novel The Time Machine), who "merged at last into a kind of hysterical exhilaration... with a kind of madness growing upon me, I flung myself into futurity". 